\title{
A COMPARATIVE SCREENING AND EVALUATION OF THE TOTAL PHENOLICS, FLAVONOIDS, AND ANTIOXIDANT PROPERTIES IN THE SEED EXTRACTS OF PUNICA GRANATUM L., PSIDIUM GUAJAVA L., AND VITIS VINIFERA L.
}

\author{
SAMBA S NELSON, SANGILIMUTHU ALAGAR YADAV* \\ Department of Biotechnology, Karpagam Academy of Higher Education, Coimbatore - 641 021, Tamil Nadu, India. \\ Email: smuthu.al@gmail.com
}

Received: 24 September 2018, Revised and Accepted: 23 October 2018

\section{ABSTRACT}

Objectives: The synthetic antioxidants produce numerous adverse effects to overcome these adverse effects and the use of natural products is the alternative. In this study, the evaluation of total phenolics, flavonoid contents, and antioxidant properties of Punica granatum, Psidium guajava, and Vitis vinifera seed extracts was done.

Methods: The total phenolic content was estimated with gallic acid equivalent and the total flavonoid contents were estimated on quercetin equivalent. For the antioxidant properties of selected seed extracts, the 2,2-diphenyl-1-picrylhydrazyl radical scavenging, ferrous reducing power, and hydrogen peroxide radical scavenging assays were followed to find the free radical scavenging ability of the selected seed extracts.

Results: The ethyl acetate extract of $P$. granatum seed contains higher phenolic content $(70.25 \pm 1.25 \mu \mathrm{g} / \mathrm{ml})$ and flavonoid content $(58.15 \pm 1.85 \mu \mathrm{g} / \mathrm{ml})$ and possesses a high free radical scavenging ability. Based on the inhibitory effects of fruit seeds against synthetic radicals, they can be ranked as P. granatum $>$ P. guajava $>$ V. vinifera.

Conclusion: According to overall observations of the study, the pomegranate seed extract contains a higher level of phenolic and flavonoid contents and shows a higher scavenging effect against free radicals among the others seeds. Phytochemical screening showed that the ethyl acetate extract of pomegranate fruit seed possesses more secondary metabolites compared to other seed extracts.

Keywords: Antioxidant, Punica granatum, Psidium guajava, Vitis vinifera, Photochemical, Flavonoid and phenolic contents, Reactive oxygen species.

(c) 2019 The Authors. Published by Innovare Academic Sciences Pvt Ltd. This is an open access article under the CC BY license (http://creativecommons. org/licenses/by/4. 0/) DOI: http://dx.doi.org/10.22159/ajpcr.2019.v12i2.29906

\section{INTRODUCTION}

Medicinal plants play a vital role in the pharmaceutical industry, and nowadays, they are meant to cure cancer and other ailments [1]. The introduction of antibiotics and other modern drugs came recently after the use of medicinal plants all over the world. Phytoflavonoids are potent water-soluble antioxidants and free radical scavengers which prevent oxidative cell damage and have strong anticancer activity. Various research evidence suggests that the free radicals induce oxidative damage in living cells and lead to various diseases, including inflammation, aging, diabetes mellitus, and cancer [2]. Effective chemotherapeutic agents have been reported from the origin of higher plants for the management of chronical diseases, nephrotoxicity, liver cirrhosis, diabetes, neurodegenerative disorders, atherosclerosis inflammation, and cancer. The reactive oxygen species play a vital role in causing various diseases in the forms of activated oxygen, such as superoxide $\left(\mathrm{O}_{2}{ }^{-}\right)$and hydroxyl radicals [3]. The studies of epidemiological clinical, experimental, $\mathrm{H}_{2} \mathrm{O}_{2}$, and singlet oxygen gives prove for work of all aerobic organisms including in the etiology of cancer. The intake antioxidant dietary components is good due to the insufficient defenøf mechanism in human antioxidants that protect against radical damage.

The metabolites and phytoconstituents from medicinal plants such as polyphenolics and flavonoids have been discovered as free potent atom scavengers [4]. The antioxidant capacity of phenolic compounds is mainly attributed to their redox properties, which enable them to react as a reducing agent, electron donor, oxygen quencher singular, or chelate [5]. The study of medicinal plants and fruits strongly support the idea that the plant constituents with antioxidant activity are capable of exerting protective effects against developing oxidative stress in the biological systems [6]. In Asia and Africa, inflammation, infections, cancer, and serious diseases are treated by folk medicine, and a large part of the population still relies on natural plants [2]. The antioxidant activities of fruit seeds in the continuation of our experimental work, the major phytoconstituents present in each extract, and the in vitro free radical scavenging potential of three edible fruit seeds such as pomegranates (Punica granatum), guava (Psidium guajava), and grapes (Vitis vinifera) were investigated. This type of fruits is cultivated in tropical and subtropical regions; they have got nutritional value with vitamins that boost human immunity. The peel, fruit, and pomace of these edible fruits have been reported for their medicinal phytoconstituents such as anti-inflammatory and antioxidants [7].

\section{METHODS}

Fruit collection and extraction of phytoconstituents Seeds of edible fruit such as pomegranate ( $P$. granatum), guava (P. guajava), and grapes (V. vinifera) were collected from juice-making industry after the extraction of juice in Coimbatore, Tamil Nadu, India.

Then, the seeds were dried under room temperature for a week and ground to powder using an electric grinder. The powdered seed materials of $P$. granatum, $P$. guajava, and $V$. vinifera $(100 \mathrm{~g})$ were exhaustively extracted using organic chemicals (petroleum ether, ethyl acetate, chloroform, methanol, and ethanol). The ratio was 1:5 (w/v) for $12 \mathrm{~h}$ using Soxhlet apparatus with 5-6 suctions. The extract was evaporated to dryness using an evaporator dish [8].

Screening of phytochemical with various organic solvent extracts of fruit seeds

Qualitative phytochemical tests on P. granatum, P. guajava, and V. vinifera seed extracts were carried out to identify the availability of the main 
phytoconstituents including alkaloids, tannins, saponins, flavonoids, cardiac glycosides, carbohydrates, amino acids, and polyphenols $[9,10]$.

\section{To estimate total phenolic contents (TPCs) in seeds extract}

The TPC of selected fruit seed extracts (petroleum ether, ethyl acetate, chloroform, methanol, and ethanol extract of P. granatum, P. guajava, and $V$. vinifera seed) was determined using gallic acid equivalence (GAE). Following Singleton et al. [11] method with modifications, the dry extracts were diluted with respective solvents, and $\mathrm{mg} / \mathrm{ml}$ of the concentration was transferred to test tubes, to which $0.5 \mathrm{ml}$ undiluted Folin-Ciocalteu reagent was added. After $1 \mathrm{~min}, 1.5 \mathrm{ml}$ of $20 \%$ (w/v) $\mathrm{Na}_{2} \mathrm{CO}_{3}$ was added and the volume made up to $10 \mathrm{ml}$ with distilled water. The reaction mixture was incubated at $25^{\circ} \mathrm{C}$ for $1 \mathrm{~h}$, and the absorbance was measured at $760 \mathrm{~nm}$ and compared with a pre-prepared gallic acid calibration curve [12]. The end point of reaction mixture was noted by the formation of blue color.

\section{To determine total flavonoid content in fruit seed extracts}

The total flavonoid contents in petroleum ether, ethyl acetate, chloroform, methanol, and ethanol extract of $P$. granatum, $P$. guajava, and $V$. vinifera fruit seeds were assessed, following Marinova et al. [13] method with a slight modification, by which $0.5 \mathrm{ml}$ of $2 \% \mathrm{AlCl}_{3}$ solution of ethanol was mixed with $1 \mathrm{ml}$ of extract $(\mathrm{mg} / \mathrm{ml})$. The $510 \mathrm{~nm}$ absorbance was measured after $1 \mathrm{~h}$ incubation at room temperature. The presence of flavonoid was indicated by a yellow color, and a quercetin equivalent was used to calculate the total flavonoid content.

\section{Antioxidant activity of fruit seed extracts}

2,2-diphenyl-1-picrylhydrazyl (DPPH) radical scavenging activity The scavenging ability of $P$. granatum, $P$. guajava, and $V$. vinifera seeds with DPPH radical was assessed $[14,15]$. Briefly, aliquot of the extracts $20-100 \mu \mathrm{g} / \mathrm{ml}$ was mixed with $3.0 \mathrm{ml} \mathrm{DPPH}(0.5 \mathrm{mmol} / \mathrm{L}$, and the absorbance was read at $517 \mathrm{~nm}$ after $30 \mathrm{~min}$ incubation at $37^{\circ} \mathrm{C}$. The following formula was arrived for the percentage of scavenging activity;

$$
\text { Percentage of inhibition }(\%)=\left[\left(\mathrm{A}_{\text {control }}-\mathrm{A}_{\text {sample }}\right) / \mathrm{A}_{\text {control }}\right] \times 100 \text {. }
$$

Where $\mathrm{A}_{\text {control }}$ - absorbance of DPPH

$A_{\text {sample }}$ - Absorbance reaction mixture (DPPH with sample).

\section{Ferrous reducing power}

The reducing ability of selected fruit seed extracts was measured according to the method of Manquian-Cerda et al. [16]. Various concentrations of extracts were mixed with $20-100 \mu \mathrm{g} / \mathrm{ml}, 0.2 \mathrm{M}, \mathrm{pH} 6.6$, and $2.5 \mathrm{ml}$ of potassium ferricyanide (1\%) with $2.5 \mathrm{ml}$ of phosphate buffer, the incubation of mixture was done at $50^{\circ} \mathrm{C}$ for 20 min with trichloroacetic acid $(10 \% ; 2.5 \mathrm{ml})$, and centrifugation was done at $3000 \mathrm{rpm}$ at $10 \mathrm{~min} .2 .5$ $\mathrm{ml}$ of distilled water was mixed with supernatant $(2.5 \mathrm{ml}), 0.5 \mathrm{ml}$ of ferric chloride $(1 \%)$ was added, and the absorbance was measured at $700 \mathrm{~nm}$. The greatest reducing power was indicated by a higher absorbance of the reaction mixture. The reducing power of guava, pomegranate, and grape seed extracts was equated with that of L-ascorbic acid.

\section{Radical scavenging activity of hydrogen peroxide}

The hydrogen peroxide atom-salvaging effects of selected fruit seed extracts were assessed [17]. Aliquots of extracts $20-100 \mathrm{~g} / \mathrm{ml}$ were added in $0.6 \mathrm{ml}$ hydrogen peroxide with phosphate buffer ( $\mathrm{pH} 7.4)$. $230 \mathrm{~nm}$ reading was made against the blank solution with phosphate buffer after the mixtures were incubated at room temperature for $10 \mathrm{~min}$, and the inhibition percentage was calculated based on the following formula:

$$
\% \text { of inhibition }=\left(A_{1}-A_{2}\right) / A_{1} 100
$$

Where $A_{1}$ - absorbance of the $\mathrm{H}_{2} \mathrm{O}_{2}$ and $\mathrm{A}_{2}$ - absorbance of the reaction mixture.

\section{Statistical analysis}

The experiments were done 3 times, and the result was evaluated as a mean standard deviation.

\section{RESULTS AND DISCUSSION}

\section{Phytochemical screening of fruit seed extracts}

The most phytochemicals were present in ethyl acetate extract of $P$. granatum fruit seed compared to that of P. guajava and V. vinifera seeds. The presence of alkaloid, flavonoids, tannins, saponins, and terpenoids in all the solvent extracts of $P$. granatum, $P$. guajava, and $V$. vinifera seeds is shown in Table 1. Compared to the selected three fruit seed extracts, the ethyl acetate extract of $P$. granatum seed extract contains more primary and secondary metabolites, which include alkaloids, flavonoids, steroids, carbohydrates, cardio glycosides, saponins, oil, fats, and terpenoids [18]. In recent years, the search for phytochemicals possessing antioxidant properties has been on the rise due to their potential use in the therapy of various chronic and infectious diseases. The phytochemical screening of the extracts revealed the presence of alkaloids, tannins, glycosides, flavonoids, and polyphenols in the extracts of petroleum ether, ethyl acetate, chloroform, methanol, and ethanol extracts of P. granatum, P. guajava, and $V$. vinifera seeds $[19,20]$.

\section{The TPC of selected fruit seed extracts}

TPC of the selected fruit seed extracts was expressed with GAEs, and the contents were obtained using regression calibration curve $\mathrm{Y}=0.603 \mathrm{X}-$ $0.5663 \mathrm{R}^{2}=0.9989$. The high TPC was observed in ethyl acetate extract of $P$. granatum $(70.25 \pm 1.25 \mu \mathrm{g} / \mathrm{ml})$, P. guajava $(58.55 \pm 1.45 \mu \mathrm{g} / \mathrm{ml})$, and V. vinifera $(60.35 \pm 0.75 \mathrm{mg} / \mathrm{l})$ among the other solvent extracts of seeds. Using the standard calibration curve of gallic acid, the TPC of different solvent extracts of $P$. guajava seeds is found at the range from $30.20 \pm 1.22$ to $58.55 \pm 1.45 \mu \mathrm{g} / \mathrm{ml}$; V. vinifera fruit seed extracts contain from $28.05 \pm 0.77$ to $60.35 \pm 0.75 \mu \mathrm{g} / \mathrm{ml}$. P. granatum fruit seed extract contains higher TPC as $70.25 \pm 1.25,58.11 \pm 1.66,43.33 \pm 1.35,40.45 \pm 1.22$, and $38.17 \pm 1.57 \mu \mathrm{g} / \mathrm{ml}$ of ethyl acetate extract, methanolic, petroleum ether, ethanol, and chloroform solvent extracts, respectively, with GAE. This shows that ethyl acetate P. granatum seed extract has a high phenolic content ability [21-23].

Numerous studies have highlighted great similarities with antioxidant biomolecules, TPC, and antioxidant activity, proving the importance of polyphenols as an effective phytoconstituents in plants [24]. Currently, there are reports which show an effective relationship between total phenolic and antioxidant activity, which appears to be the trend in many plant species. Hence, phenolic and flavonoid compounds seem to have antioxidant activity that plays an important role in stabilizing lipid reduction. The higher antioxidant activity in this study arises from the high phenolic content of the fruit seed extracts [25].

\section{To determine total flavonoid content}

Using the regression calibration curve with quercetin equivalent $\left(\mathrm{Y}=0.1211 \mathrm{X}-0.129 \mathrm{R}^{2}=0.9985\right)$, the total flavonoid content of selected fruit seeds is arrived at. Among the different solvent extracts of seeds ( $P$. granatum, $P$. guajava, and $V$. vinifera), the ethyl acetate extract of seeds contains higher flavonoid content. The results show the total flavonoid contents as $55.45 \pm 1.15,48.55 \pm 1.15$, and $58.15 \pm 1.85 \mu \mathrm{g} / \mathrm{ml}$ of ethyl acetate extract of P. guajava, $V$. vinifera and $P$. granatum seeds, respectively. In different solvent extracts, $P$. guajava seed contains the total flavonoid content ranging $24.15 \pm 1.35-55.45 \pm 1.15 \mu \mathrm{g} / \mathrm{ml}$ and $V$. vinifera fruit seed ranging $30.85 \pm 2.15-48.55 \pm 1.15 \mu \mathrm{g} / \mathrm{ml}$. Using the standard calibration curve with quercetin, the total flavonoid contents of $P$. granatum fruit seed extracts are found to be $58.15 \pm 1.85,54.45 \pm 2.65$, $44.15 \pm 2.25,37.25 \pm 1.35$, and $29.50 \pm 0.95 \mu \mathrm{g} / \mathrm{ml}$ on ethyl acetate, methanol, chloroform, petroleum ether, and ethanol extract of $P$. granatum, respectively, with quercetin equivalent [26]. In vitro antioxidant assay of selected fruit seed extracts DPPH radical scavenging activity The petroleum ether, ethyl acetate, chloroform, methanolic, and ethanol extracts of P. granatum, P. guajava, and V. vinifera seeds showed good 
antioxidant capacity and higher inhibitory activity in ethyl acetate extract of $P$. granatum (half maximal inhibitory concentration $\left[\mathrm{IC}_{50}\right]$ $30.70 \pm 0.78 \mu \mathrm{g} / \mathrm{ml}$ ) seed against synthetic free atoms compared to the L-ascorbic acid $(22.15 \pm 0.5 \mu \mathrm{g} / \mathrm{ml})$. The decreasing absorbance was observed in the DPPH radical scavenging activity due to the scavenging ability of the extracts [4]. The percentage inhibition of different solvent extracts of $P$. granatum, P. guajava, and $V$. vinifera against synthetic free radical ranges from $17 \%$ to $65 \%$ (Figs. 1-3). The least $\mathrm{IC}_{50}$ value is found in the ethyl acetate extract of selected fruits compared to the other solvent extracts (Table 2). The $\mathrm{IC}_{50}$ value of L-ascorbic acid is $22.15 \pm 0.5 \mu \mathrm{g} / \mathrm{mg}$. A lower $\mathrm{IC}_{50}$ value indicates a higher potential of the extracts. The ability of DPPH radical scavenging activity is higher in $P$. granatum extract compared to other extracts $[27,28]$. Reported that, plant fractions inhibit the DPPH radicals in an independent manner with similar findings, as ethyl acetate fractions of strawberry contain more inhibitory effects.

The antioxidant activity of the extracts was conducted based on their ability to trap DPPH atom. DPPH is a stable free radical method which is a sensitive way to determine the free radical and hydrogen atom to attract an electron or hydrogen radical to become a stable magnetic molecule. The free radicals are involved in various disorders such as neurodegenerative diseases and cancer [5]. The extracts were tested for free radical scavenging ability with synthetic free radical (DPPH) which inhibited the free radical in increasing the concentration of the extracts. This result proved that the seed extracts were capable of giving an electron or hydrogen which could react with DPPH radical. The variation observed between the scavenging activities of the extracts depended on the type of fruit seeds and solvent used for the study. These differences could be attributed to an unequal distribution of the antioxidant phytomolecules such as polyphenol, flavonoids, and alkaloids, identified in the different concentrations of fruit seeds [29].

The extract of the ethyl acetate $P$. granatum fruit seed extract has a high free-atom salvaging activity. Many categories of phytocompounds which play a symbiotic role are obtained from extracts to boost the biological activity. Moreover, the antioxidant activity of these extracts to give hydrogen or electron atom to entrap DPPH atom depends on its presence [30].

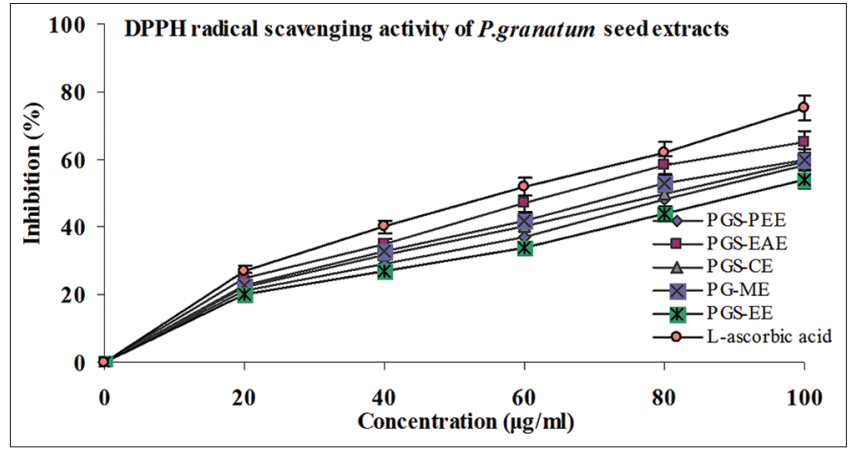

Fig. 1: Inhibitory effect of Punica granatum seed extracts against 2,2-diphenyl-1-picrylhydrazyl radical. PGS-PEE: Petroleum ether extract of Punica granatum seed, PGS-EAE: Ethyl acetate extract of Punica granatum seed, PGS-CE: Chloroform extract of Punica granatum seed, PGS-ME: Methanol extract of Punica granatum seed, PGS-EE: Ethanol extract of Punica granatum seed

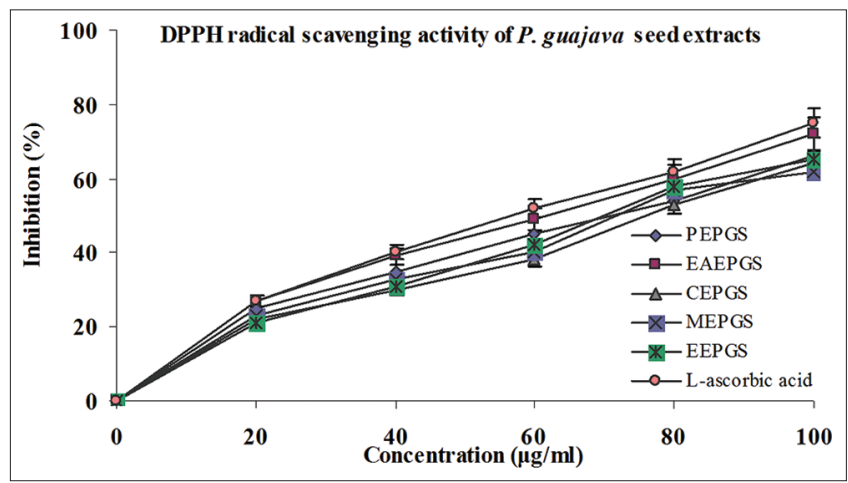

Fig. 2: Inhibitory effect of Psidium guajava seed extracts against 2,2-diphenyl-1-picrylhydrazyl radical. PE-PGS: Petroleum ether extract of Psidium guajava seed, EAE-PGS: Ethyl acetate extract of Psidium guajava seed, CE-PGS: Chloroform extract of Psidium guajava seed, ME-PGS: Methanol extract of Psidium guajava seed, EE-PGS: Ethanol extract of Psidium guajava seed

Table 1: Screening of major phytochemicals in selected fruit seed extracts

\begin{tabular}{|c|c|c|c|c|c|c|c|c|c|c|c|c|c|c|c|}
\hline \multirow{2}{*}{$\begin{array}{l}\text { Seed extracts major } \\
\text { phytochemicals }\end{array}$} & \multicolumn{5}{|c|}{ V. vinifera seed extracts using } & \multicolumn{5}{|c|}{ P. guajava seed extracts using } & \multicolumn{5}{|c|}{ P. granatum seed extract using } \\
\hline & P.E & E.A & $\mathrm{Ch}$ & $\mathbf{M}$ & $\mathbf{E}$ & P.E & E.A & Ch & $\mathbf{M}$ & $\mathbf{E}$ & P.E & E.A & Ch & $\mathbf{M}$ & $\mathbf{E}$ \\
\hline Alkaloids & - & + & - & + & - & - & + & - & + & - & - & + & + & + & - \\
\hline Steroids & - & + & - & - & - & + & - & - & + & + & + & + & + & - & - \\
\hline Flavonoids & - & + & + & + & + & - & + & - & + & + & - & + & - & + & + \\
\hline Tannins & - & + & + & + & + & - & + & + & - & + & - & - & + & + & - \\
\hline Amino acids & - & - & - & - & - & + & - & + & - & - & - & - & - & + & - \\
\hline Carbohydrates & - & - & - & + & + & - & + & - & + & + & - & + & - & + & + \\
\hline Cardio glycosides & - & - & - & + & + & - & - & - & + & - & - & + & + & - & + \\
\hline Saponins & - & + & + & + & - & - & + & + & + & - & - & + & - & - & + \\
\hline Oils and fats & + & - & - & - & - & + & - & + & - & - & + & + & - & - & - \\
\hline Terpenoids & + & - & + & - & - & - & + & + & - & - & + & + & + & + & - \\
\hline
\end{tabular}

+Positive, -Negative, P.E: Petroleum ether, E.A: Ethyl acetate, Ch: Chloroform, M: Methanol, E: Ethanol. P. granatum: Punica granatum, P. guajava: Psidium guajava,

V. vinifera: Vitis vinifera

Table 2: $\mathrm{IC}_{50}$ value of seed extracts against DPPH

\begin{tabular}{llll}
\hline & P. granatum seed extracts $\boldsymbol{\mu g} / \mathbf{m l}$ & P. guajava seed extracts $\boldsymbol{\mu g} / \mathbf{m l}$ & V. vinifera seed extracts $\boldsymbol{\mu g} / \mathbf{m l}$ \\
\hline Petroleum ether extract & $45.60 \pm 1.50$ & $48.5 \pm 1.1$ & $45.2 \pm 0.9$ \\
Ethyl acetate extract & $30.70 \pm 0.78$ & $35.15 \pm 1.05$ & $40.10 \pm 0.80$ \\
Chloroform extract & $52.80 \pm 2.60$ & $55.55 \pm 1.3$ & $59.05 \pm 0.6$ \\
Methanol extract & $38.70 \pm 0.1$ & $40.15 \pm 0.75$ & $51.2 \pm 0.10$ \\
Ethanol extract & $56.95 \pm 0.80$ & $59.48 \pm 0.7$ & $63.5 \pm 0.35$ \\
\hline
\end{tabular}


Ferrous reducing power of selected fruit seed extracts

The ferrous reducing power of the selected fruit seed extracts shows an increasing absorbance with increasing concentration of the samples. In Figs. 4-6, the high antioxidant capacity of the extracts is indicated by the higher absorbance value. The result gives an important value on ethyl acetate extract of $P$. granatum seed compared to the other extracts. The outcome shows that the extract contains ferric $\left(\mathrm{Fe}^{3+}\right)$ reduction ability to $\mathrm{Fe}^{2+}$ [31]. In proving the antioxidant capacity of the extract, similarity was noted in previous reports of capuli fruits and berries by Songsermsakul et al. [32].

Hydrogen peroxide radical scavenging activity

The radical scavenging ability of hydrogen peroxide of the selected fruit seed extracts is demonstrated. The inhibition percentage for

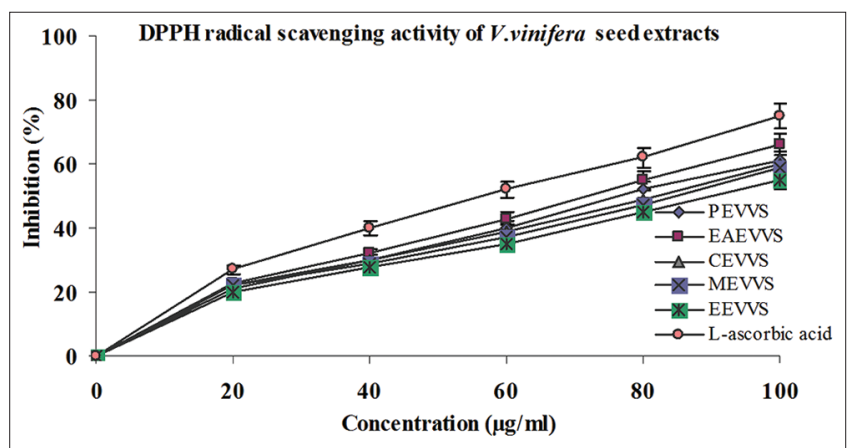

Fig. 3: Inhibitory effect of Vitis vinifera seed extracts against DPPH radical. PE-VVS: Petroleum ether extract of Psidium guajava seed, EAE-VVS: Ethyl acetate extract of Psidium guajava seed, CE-VVS: Chloroform extract of Psidium guajava seed, ME-VVS: Methanol extract of Psidium guajava seed, EE-VVS: Ethanol extract of Psidium guajava seed

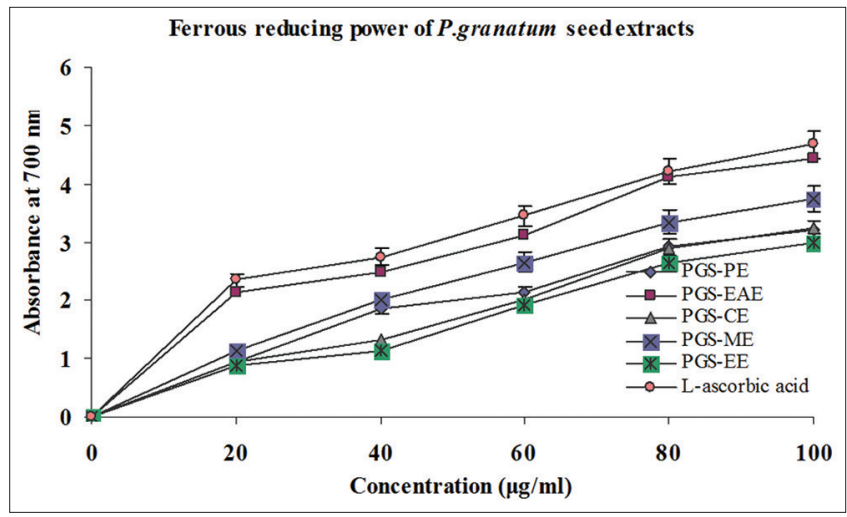

Fig. 4: Ferrous reducing power of Punica granatum seed extracts. PGS-PEE: Petroleum ether extract of Punica granatum seed, PGS-EAE: Ethyl acetate extract of Punica granatum seed, PGS-CE: Chloroform extract of Punica granatum seed, PGS-ME: Methanol extract of Punica granatum seed PGS-EE: Ethanol extract of Punica granatum seed selected seed extracts against $\mathrm{H}_{2} \mathrm{O}_{2}$ atoms ranges between $25 \%$ and 65\% (Figs. 7-9), and the ethyl acetate extract of P. granatum, P. guajava, and $V$. vinifera seeds is found to have higher inhibition in relating to other organic solvent extracts of seeds. The $\mathrm{IC}_{50}$ value of the extracts as shown in Table. 3 shows that the ethyl acetate extract of selected seeds (P. granatum, P. guajava, and $V$. vinifera) has potent inhibitory effects with less concentration of the extracts. The results show that the P. granatum seed contains more hydrogen peroxide radical scavenging activity compared to P. guajava and V. vinifera seed extracts. The standard used is L-ascorbic acid and $\mathrm{IC}_{50} 40.22 \pm 0.44 \mu \mathrm{g} / \mathrm{ml}$. The antioxidant activity of selected fruit seed extract shows a high antioxidant level on ethyl acetate $P$. granatum seed extracts in relation to $P$. guajava and $V$. vinifera solvent extracts [33].

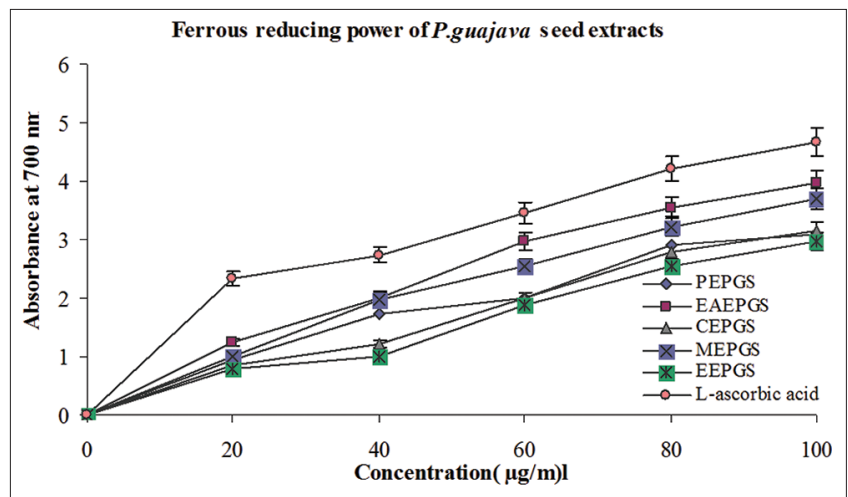

Fig. 5: Ferrous reducing power of Psidium guajava seed extracts. PE-PGS: Petroleum ether extract of Psidium guajava seed, EAE-PGS: Ethyl acetate extract of Psidium guajava seed, CE-PGS: Chloroform extract of Psidium guajava seed, ME-PGS: Methanol extract of Psidium guajava seed, EE-PGS: Ethanol extract of Psidium guajava seed)

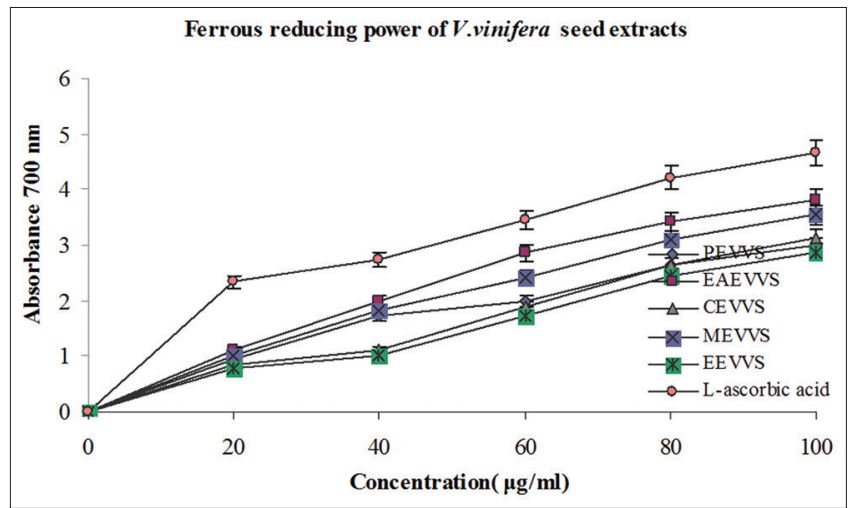

Fig. 6. Ferrous reducing power of Vitis vinifera seed extracts. PE-VVS: Petroleum ether extract of Psidium guajava seed, EAE-VVS: Ethyl acetate extract of Psidium guajava seed, CE-VVS: Chloroform extract of Psidium guajava seed, ME-VVS: Methanol extract of Psidium guajava seed, EE-VVS: Ethanol extract of Psidium guajava seed

Table 3: $\mathrm{IC}_{50}$ value of seed extracts against $\mathrm{H}_{2} \mathrm{O}_{2}$

\begin{tabular}{llll}
\hline Fruit seeds organic solvent extracts & P. granatum seed extracts $\boldsymbol{\mu g} / \mathbf{m l}$ & P. guajava seed extracts $\boldsymbol{\mu g} / \mathbf{m l}$ & V. vinifera seed extracts $\boldsymbol{\mu g} / \mathbf{m l}$ \\
\hline Petroleum ether extract & $59.98 \pm 0.44$ & $62.53 \pm 0.56$ & $67.58 \pm 0.66$ \\
Ethyl acetate extract & $45.05 \pm 1.15$ & $50.15 \pm 1.75$ & $52.11 \pm 0.44$ \\
Chloroform extract & $63.22 \pm 0.77$ & $65.05 \pm 0.45$ & $72.55 \pm 0.66$ \\
Methanol extract & $52.22 \pm 0.34$ & $57.56 \pm 0.77$ & $60.88 \pm 0.64$ \\
Ethanol extract & $65.5 \pm 0.22$ & $72.88 \pm 0.98$ & $78.54 \pm 0.88$ \\
\hline
\end{tabular}

$\mathrm{IC}_{5}$ : Half maximal inhibitory concentration, $P$. granatum: Punica granatum, P. guajava: Psidium guajava, V. vinifera: Vitis vinifera 


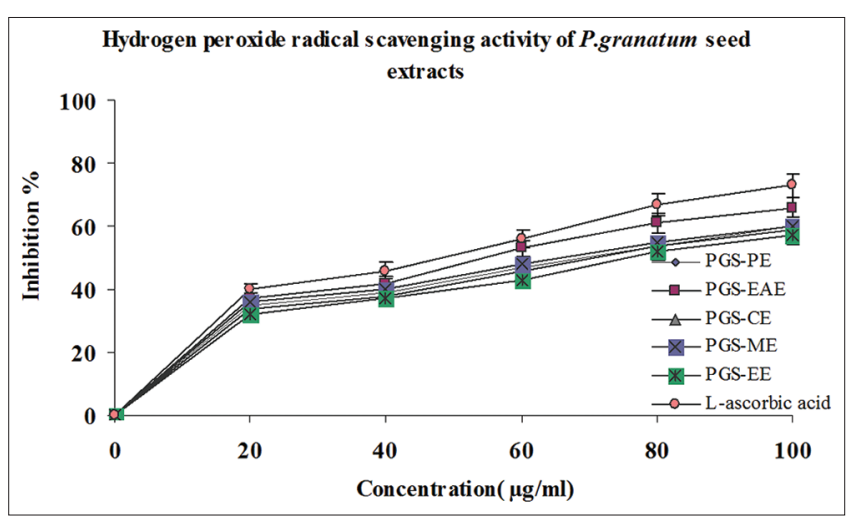

Fig. 7: Inhibitory effect of Punica granatum seed extracts against $\mathrm{H}_{2} \mathrm{O}_{2}$ radical. PGS-PEE: Petroleum ether extract of Punica granatum seed, PGS-EAE: Ethyl acetate extract of Punica granatum seed, PGS-CE: Chloroform extract of Punica granatum seed, PGS-ME: Methanol extract of Punica granatum seed, PGS-EE: Ethanol extract of Punica granatum seed

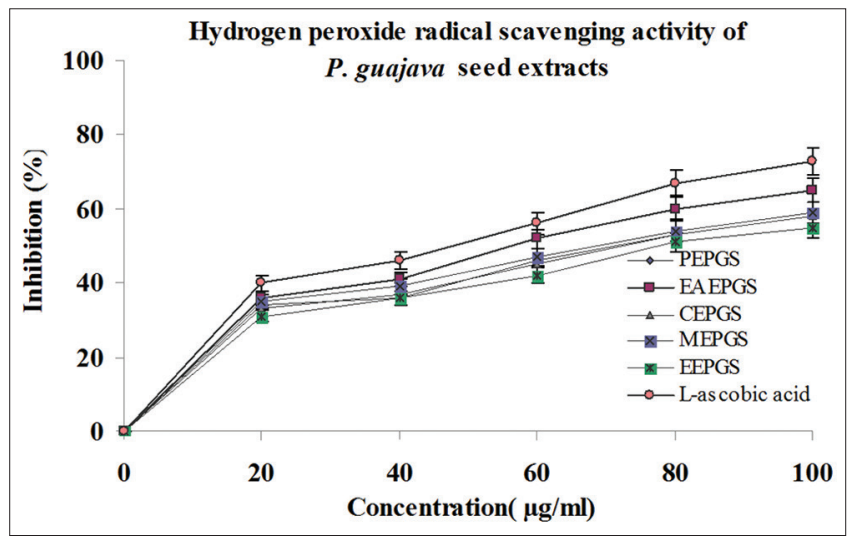

Fig. 8: Inhibitory effect of Psidium guajava seed extracts against $\mathrm{H}_{2} \mathrm{O}_{2}$ radical. PE-PGS-Petroleum ether extract of Psidium guajava seed, EAE-PGS: Ethyl acetate extract of Psidium guajava seed, CE-PGS: Chloroform extract of Psidium guajava seed, ME-PGS: Methanol extract of Psidium guajava seed, EE-PGS: Ethanol extract of Psidium guajava seed

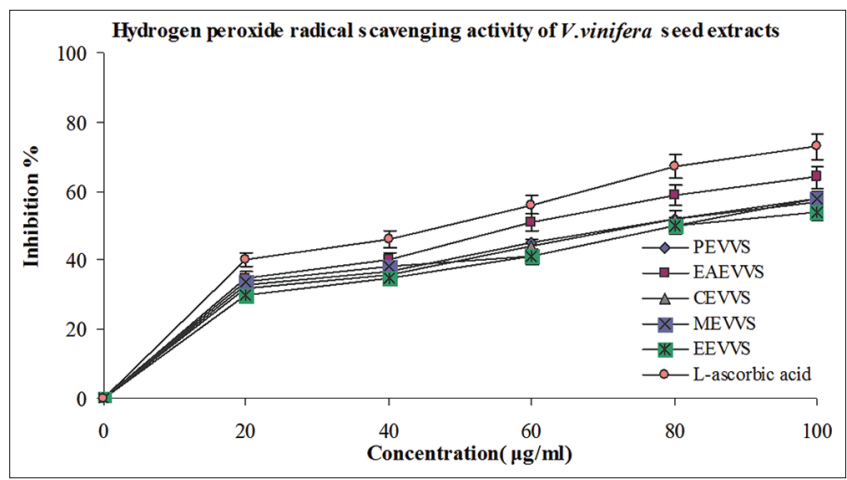

Fig. 9: Inhibitory effect of Vitis vinifera seed extracts against $\mathrm{H}_{2} \mathrm{O}_{2}$ radical. PEV-VS: Petroleum ether extract of Psidium guajava seed, EAE-VVS: Ethyl acetate extract of Psidium guajava seed, CE-VVS: Chloroform extract of Psidium guajava seed, ME-VVS: Methanol extract of Psidium guajava seed, EE-VVS: Ethanol extract of Psidium guajava seed

Hydroxyl atoms in biological system, which are among the most reactive species, are known to be extremely damaging, and hence, many plants have antioxidant activities that are useful for health [34]. In this finding, the antioxidant potential of a compound is attributed to the salvaging activity of these atoms as best precursors [35].

There is a perfect correlation among the antioxidant activity (DPPH, TPC, total flavonoid content, ferrous reducing power, and hydrogen peroxide radical scavenging), aiding the idea of polyphenols as a fundamental power of the antioxidant and anticancer properties of fruit seed extracts. Evaluation needs to be done, extensively to isolate the in vitro antioxidant compounds or to determine the biological activity of these extracts [36]

\section{CONCLUSION}

In the fruit juice industry, the seeds of various fruits are thrown as waste, disposing the fruit waste leads to the higher cost, and environmental damage during the land-fills. From the discharge, the collected seeds of $P$. granatum, $P$. guajava, and $V$. vinifera have been explored in a useful manner to treat them against reactive oxygen species. The ethyl acetate extracts of $P$. granatum, $P$ guajava, and $V$. vinifera seeds contain higher phenolic and flavonoid content and high free atom salvaging inhibitory properties compared to other chemical extracts of selected seeds. Among the three selected seeds, $P$. granatum seed contains more phytoconstituents, high phenolic and flavonoid contents, and high antioxidant potential. The antioxidant inhibitory potentials of the selected seeds are ranked as $P$. granatum $>P$. guajava $>V$. vinifera

\section{ACKNOWLEDGMENT}

Authors are grateful to the management of Karpagam Academy of Higher Education for providing the laboratory facilities to carry out the research work.

\section{AUTHORS' CONTRIBUTIONS}

Author YAS designed the work and modified the required correction in the manuscript; NSS executed the research work and written the manuscript.

\section{CONFLICTS OF INTEREST}

The authors declare that they have no competing interests and also there are no conflicts of interest among them.

\section{REFERENCES}

1. Ha KS, Jo SH, Mannam V, Kwon YI, Apostolidis E. Stimulation of phenolics, antioxidant and $\alpha$-glucosidase inhibitory activities during barley (Hordeum vulgare L.) seed germination. Plant Food Hum Nutr 2016;71:211-7.

2. Hitayezu R, Baakdah MM, Kinnin J, Henderson K, Tsopmo A. Antioxidant activity, avenanthramide and phenolic acid contents of oat milling fractions. J Cereal Sci 2015;63:35-40.

3. Ashraf A, Sarfraz RA, Rashid MA, Shahid M. Antioxidant, antimicrobial, antitumor, and cytotoxic activities of an important medicinal plant (Euphorbia royleana) from Pakistan. J Food Drug Anal 2015;23:109-15.

4. Yadav SA, Ramalingam S, Jebamalairaj A, Subban R, Sundaram KM. Biochemical fingerprint and pharmacological applications of Barleria noctiflora Lf leaves. J Complement Integr Med 2016;13:365-76.

5. Zhang Z, Kong F, Ni H, Mo Z, Wan JB, Hua D, et al. Structural characterization, $\alpha$-glucosidase inhibitory and DPPH scavenging activities of polysaccharides from guava. Carbohydr Polym 2016;144:106-14

6. Widyawati PS, Budianta TD, Gunawan DI, Wongso RS. Evaluation antidiabetic activity of various leaf extracts of Pluchea indica Less. IJPPR 2015;7:597-603.

7. Muredzi ED. Food is Medicine-An Introduction to Neutraceuticals. London: Academic Press; 2013.

8. Mishra A, Mishra AK, Jain SK. Anticonvulsant activity of Cleome viscosa seed extracts in Swiss albino mice. Int $\mathrm{J}$ Pharm Pharm Res 2010;2:177-81

9. Trease GE, Evans WC. Textbook of Pharmacognosy. London: Academic Press; 1989. 
10. Harborne JB. Phytochemical Methods: A Guide to Modern Technique of Plant Analysis. London: Chapman and Hall; 1973.

11. Singleton VL, Orthofer R, Lamuela-Raventos RM. Analysis of total phenols and other oxidation substrates and antioxidants by means of folin-ciocalteu reagent. Methods Enzymol 1999;299:152-78.

12. Yadav SA, Raj AJ, Sathishkumar R. In vitro antioxidant activity of Barleria noctiflora L. f. Asian Pac J Trop Biomed 2012;2:S716-22.

13. Marinova D, Ribarova F, Atanassova M. Total phenolics and total flavonoids in Bulgarian fruits and vegetables. JUCTM 2005;40:255-60.

14. Zhu Y, Li T, Fu X, Abbasi AM, Zheng B, Shahidi F. Phenolics content, antioxidant and antiproliferative activities of dehulled highland barley (Hordeum vulgare L.). J Funct Foods 2015;19:439-50.

15. Pu X, Ma X, Liu L, Ren J, Li H, Li X, et al. Structural characterization and antioxidant activity in vitro of polysaccharides from Angelica and Astragalus. Carbohydr Polym 2016;137:154-64.

16. Manquian-Cerda K, Escudey M, Zuniga G, Arancibia-Miranda N, et al. Effect of cadmium on phenolic compounds, antioxidant enzyme activity and oxidative stress in blueberry (Vaccinium corymbosum L.) plantlets grown in vitro. Ecotoxicol Environ Saf 2016;133:316-26.

17. Garcimartin A, Lopez-Oliva ME, Gonzaez MP, Sanchez-Muniz FJ, Benedi J. Hydrogen peroxide modifies both activity and isoforms of acetylcholinesterase in human neuroblastoma SH-SY5Y cells. Redox Biol 2017;12:719-26.

18. Yadav SA, Ramalingam S, Raj AJ, Subban R. Antihistamine from Tragia involucrata L. leaves. J Complement Integr Med 2015;12:217-26.

19. Ghaima KK, Hashim NM, Ali SA. Antibacterial and antioxidant activities of ethyl acetate extract of nettle (Urtica dioica) and dandelion (Taraxacum officinale). J Appl Pharm Sci 2013;3:96.

20. Skrovankova S, Sumczynski D, Mlcek J, Jurikova T, Sochor J. Bioactive compounds and antioxidant activity in different types of berries. Int $\mathrm{J}$ Mol Sci 2015;16:24673-706.

21. Priya SH, Prakasan N, Purushothaman J. Antioxidant activity, phenolicflavonoid content and high-performance liquid chromatography profiling of three different variants of Syzygium cumini seeds: A comparative study. J Intercult Ethnopharm 2017;6:107.

22. Derakhshan Z, Ferrante M, Tadi M, Ansari F, Heydari A, Hosseini MS, et al. Antioxidant activity and total phenolic content of ethanolic extract of pomegranate peels, juice and seeds. Food Chem Toxicol 2018;114:108-11.

23. Jara-Palacios MJ, Hernanz D, Escudero-Gilete ML, Heredia FJ. Antioxidant potential of white grape pomaces: Phenolic composition and antioxidant capacity measured by spectrophotometric and cyclic voltammetry methods. Food Res Int 2014;66:150-7.

24. Qasim M, Abideen Z, Adnan MY, Gulzar S, Gul B, Rasheed M, et al. Antioxidant properties, phenolic composition, bioactive compounds and nutritive value of medicinal halophytes commonly used as herbal teas. S Afri J Bot 2017;110:240-50.

25. Barcia MT, Pertuzatti PB, Rodrigues D, Gomez-Alonso S, HermosinGutierrez I, et al. Occurrence of low molecular weight phenolics in Vitis vinifera red grape cultivars and their winemaking by-products from Sao Paulo (Brazil). Food Res Int 2014;62:500-13.

26. Lei Y, Chen Q, Chen J, Liu D. Potential ameliorative effects of grape seed-derived polyphenols against cadmium induced prostatic deficits. Biomed Pharm 2017;91:707-13.

27. Wozniak L, Skąpska S, Marszałek K. Ursolic acid a pentacyclic triterpenoid with a wide spectrum of pharmacological activities. Molecules 2015;19:20614-41.

28. Giampieri F, Alvarez-Suarez JM, Mazzoni L, Forbes-Hernandez TY, Gasparrini M, Gonzalez-Paramas AM, et al. An anthocyanin-rich strawberry extract protects against oxidative stress damage and improves mitochondrial functionality in human dermal fibroblasts exposed to an oxidizing agent. Food Funct 2014;5:1939-48.

29. Drosou C, Kyriakopoulou K, Bimpilas A, Tsimogiannis D, Krokida M. A comparative study on different extraction techniques to recover red grape pomace polyphenols from vinification byproducts. Ind Crops Prod 2015;75:141-9.

30. Dudonne S, Vitrac X, Coutiere P, Woillez M, Meerillon JM. Comparative study of antioxidant properties and total phenolic content of 30 plant extracts of industrial interest using DPPH, ABTS, FRAP, SOD, and ORAC assays. J Agric Food Chem 2009;57:1768-74.

31. Chua LS, Lau CH, Chew CY, Ismail NI, Soontorngun N. Phytochemical profile of Orthosiphon aristatus extracts after storage: Rosmarinic acid and other caffeic acid derivatives. Phytomedicine 2018;39:49-55.

32. Jacobo-Velazquez DA, Cisneros-Zevallos L. Correlations of antioxidant activity against phenolic content revisited: A new approach in data analysis for food and medicinal plants. J Food Sci 2009;74:107-13.

33. Songsermsakul P, Pornphairin E, Porasuphatana S. Comparison of antioxidant activity of grape seed extract and fruits containing high $\beta$-carotene, Vitamin C, and E. Int J Food Prop 2013;16:643-8.

34. Trepiana J, Ruiz-Larrea MB, Ruiz-Sanz JI. Unraveling the in vitro antitumor activity of Vismia baccifera against HepG2: Role of hydrogen peroxide. Heliyon 2018;4:e0675.

35. Tournour HH, Segundo MA, Magalhaes LM, Barreiros L, Queiroz J, et al. Valorization of grape pomace: Extraction of bioactive phenolics with antioxidant properties. Ind Crops Prod 2015;74:397-406.

36. Durdevic S, Savikin K, Zivkovic J, Bohm V, Stanojkovic T, Damjanovic A, et al. Antioxidant and cytotoxic activity of fatty oil isolated by supercritical fluid extraction from microwave pretreated seeds of wild growing Punica granatum L. J Supercrit Fluids 2018;133:225-32. 